\title{
AN EXPERIMENTAL STUDY ON THE MECHANICAL PROPERTIES
}

\section{OF BASALT AND BANANA FIBER REINFORCED}

\section{HYBRID POLYMER COMPOSITES}

\section{ADITYA DOGRA ${ }^{1}$, AKSHINA SONI ${ }^{1} \&$ YOGEESHA PAI ${ }^{2}$}

${ }^{1}$ UG Students, Department of Aeronautical \& Automobile Engineering, MIT-MAHE, Manipal, India

${ }^{2}$ Assistant Professor, Department of Aeronautical \& Automobile Engineering, MIT-MAHE, Manipal, India

ABSTRACT
Natural fiber composites are nowadays being used in various engineering applications for the fabrication of
lightweight, low cost polymer composites. This is mainly attributed to the use of eco-friendly materials which are easy
to use and dispose and has no negative impacts on the environment. The objective of this research work is to
experimentally determine the mechanical and thermal properties of Basalt-Banana composite laminates and to find
out the degree of improvement due to the addition of Basalt layers on the tensile strength, flexural strength and other
properties of Banana fiber composite. Laminates were prepared by hand layup followed by Vacuum-bagging. Each
laminate consisting of 5 layers in the intercalated sequence Basalt /Banana/ Basalt/ Banana/ Basalt. The results were
finally compared with the existing work on Glass - Banana Fiber composites.
KEYWORDS: Natural Fiber, Banana Fiber, Basalt Fiber, Vacuum Bagging \& Mechanical Characterization

Received: Nov 25, 2018; Accepted: Dec 15, 2018; Published: Jan 05, 2019; Paper Id.: IJMPERDFEB201925

\section{INTRODUCTION}

The study of natural fiber composite is rapidly increasing in recent years due to the growing awareness of more eco-friendly products and to protect the environment. Researchers everywhere are focusing on developing new materials that would improve the eco-friendly quality of products. Natural fiber composites also help to control pollution problems which is the major source of pollution by the synthetic materials [1]. Banana fibers are most abundantly available natural fibers. Basalt fibers are generally used as an alternative to glass fibers due to many advantages.

Natural fibers have many advantages such as low density, better specific tensile properties, low cost, nonabrasive to the equipment, less energy consumption, reduced health risks, biodegradable, less irritation to the skin, renewable and recyclable when compared to man-made synthetic fibers such as glass and carbon[2].

\section{METHODOLOGY}

The banana-basalt fiber reinforced composites are fabricated by hand lay-up process then cured using vacuum bagging technique. 


\section{Materials Used}

The natural Banana fiber was purchased from Kovai Green fibers, Coimbatore in Tamil Nadu. Woven Basalt Fiber mats of 400 GSM from Nickunj Entp. Pvt. Ltd., Mumbai. Epoxy resin L-12 and hardener K-6 were purchased from Achyuth Chemicals in Bangalore.
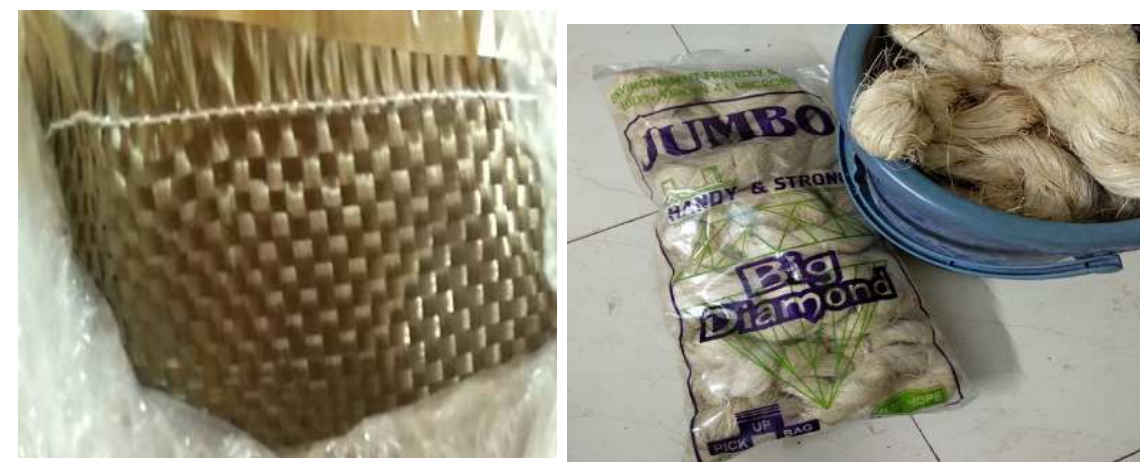

Figure 1: Woven Basalt and Raw Banana Fiber

\section{Fiber Treatment}

The banana fibres were dusted and cleaned for any extra macro impurities and then soaked in $1 \% \mathrm{NaOH}$ solution and left submerged for 30 minutes. The $1 \% \mathrm{NaOH}$ treatment results in nearly $50 \%$ increase in the properties of the composite when compared with the untreated fiber reinforced composite [3]. Fibers were taken out and washed with running water till their $\mathrm{pH}$ turned to neutral. This was checked using a $\mathrm{pH}$ paper. The fibers were then dried in the sunlight for 2 days and were combed to get uniform length strands suitable for fabrication and to remove any other physical impurities if present.

\section{Fabrication Procedure}

Manual hand layup method followed by vacuum bagging was adopted for fabricating composite laminates. Unidirectional banana mat were prepared of size $30 \times 30 \mathrm{~cm}$. Composite laminates were fabricated in an intercalated sequence using 3 basalt fiber layers and 2 banana fiber layers. The stacking sequence adopted was Basalt/ Banana/ Basalt/ Banana/ Basalt.

The base plate was cleaned and gel coating was applied on it followed by resin-hardener combination. The basaltbanana layers were kept in the selected order and resin-hardener combination was applied between each of the layers and a roller was used to increase uniformity of surface and remove any air bubbles. The top layer was covered with p-ply fabric and breather. The arrangement was then covered with vacuum bag with a hole at the corner which was connected to the vacuum pump nozzle. The bag was sealed along its edges. The vacuum pump was stopped after 1 hour and a curing time of 17 hours was given. The composite was taken out and its edges were trimmed and was cut into appropriate sizes for testing as shown in figure 2 . 

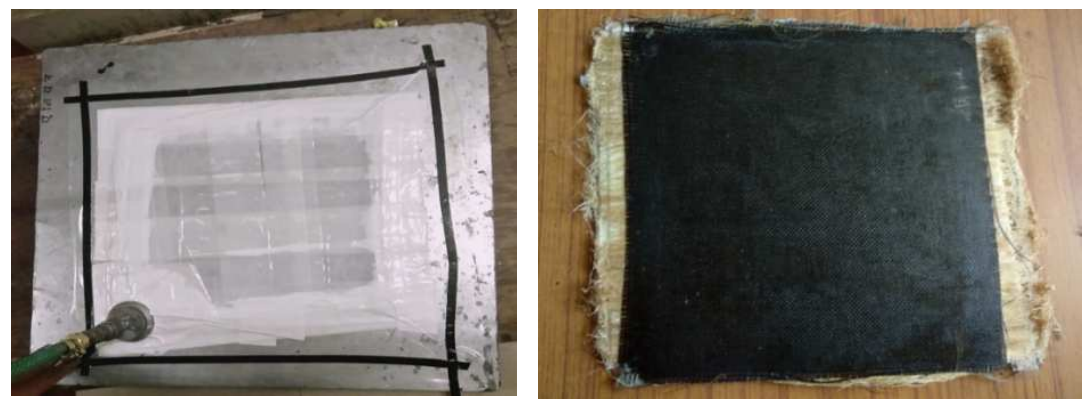

Figure 2: Vacuum Bagging Process and Cured Banana-Basalt Composite

\section{RESULTS \& DISCUSSIONS}

\section{Tensile Properties}

The tensile test was done on the Universal Testing Machine UNITEK 9450 according to the ASTM standards. The results of the test are as shown below according to which the Young's Modulus of the laminate is $3.67 \mathrm{GPa}$ and the Tensile strength is $73 \mathrm{MPa}$.

The Stress Vs Strain curves of the laminates were obtained as shown in figure 3, which shows the maximum stress applied on the laminate. Figure 4shows the tensile strength values of various laminates [4] [5] [6] [7]. We can observe that addition of plain woven basalt-fiber layers in the Banana-epoxy composite increases the tensile Strength of the laminates by 4 times. It is also evident that replacing glass fiber layer with basalt fiber increases the tensile strength by 84 $\%$.

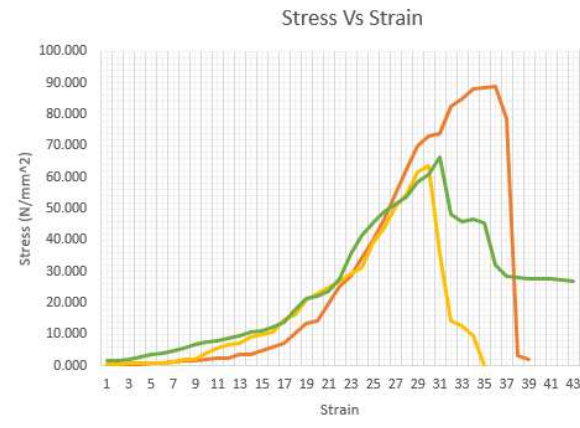

Figure 3: Stress-Strain Curve of Laminates

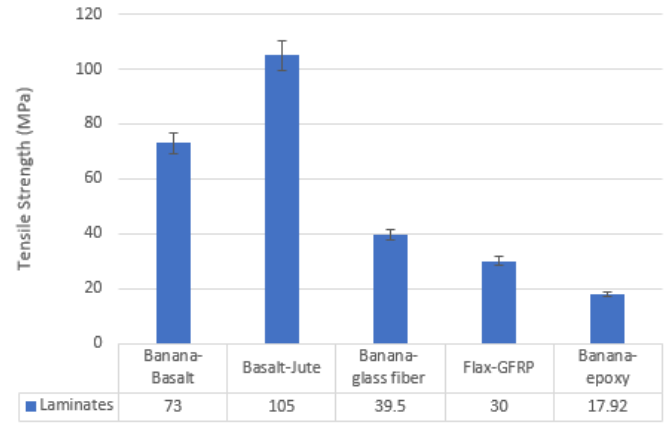

Figure 4: Tensile Strength of Various Laminates

\section{Flexural Properties}

Three-point bending test of three samples was done in the UTM according to ASTM D790. The Brittle collapse of the samples was observed at the Ultimate load and the crack propagated from the external basalt layers to the interior region.

The flexural strength measurements revealed that composite with basalt fiber layers between banana fibers have greater flexural strength compared to the one with glass fiber layer between banana fibers. 


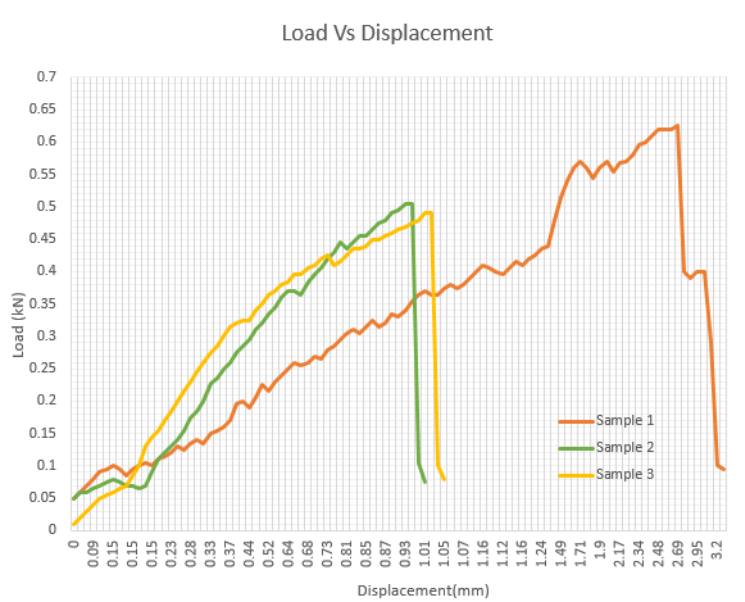

Figure 5: Load Vs Displacement Curve for Samples

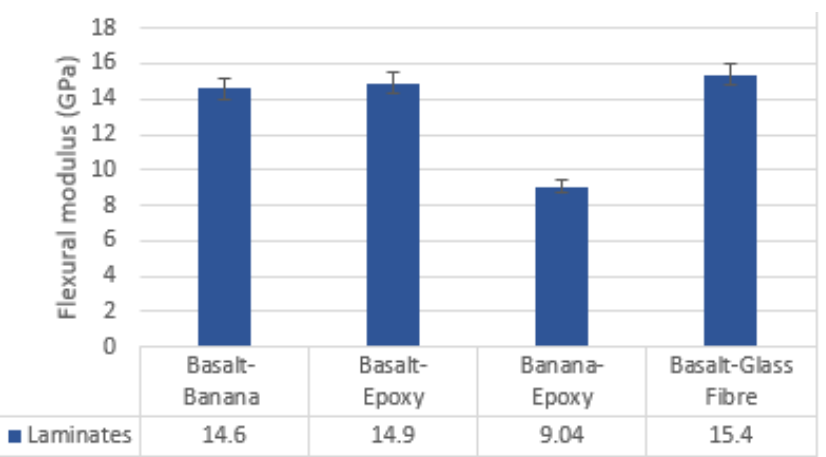

Figure 6: Flexural Modulus of Various Laminates

The maximum and minimum load applied are $625 \mathrm{~N}$ and $490 \mathrm{~N}$ respectively. The average flexural modulus is found to be $14.6 \mathrm{GPa}$ and the average flexural strength is $354.3 \mathrm{MPa}$ as shown in figure 5 .

The comparison of flexural modulus of different composite laminates is shown in figure 6 [7][8][9]. It shows that the addition of basalt fiber layers with banana fiber increases the flexural modulus of the composite by $61 \%$. It is also evident that the flexural stiffness of the basalt-banana laminate is slightly lower to the basalt-glass fiber epoxy[9] composite. It can also be observed that flexural strength of glass-banana composite laminate is $101 \%$ lower than that of basalt-banana composite. Hence, it can be concluded that addition of basalt fiber layers in the banana - epoxy composite increases the flexural resistance of the composite laminate.

\section{Impact Properties}

The impact test was carried out for analysing the impact load of three samples. Izod impact machine was used to determine the amount of energy lost during the test. The energy absorbed by the specimen and the resistance to impact is shown below. 


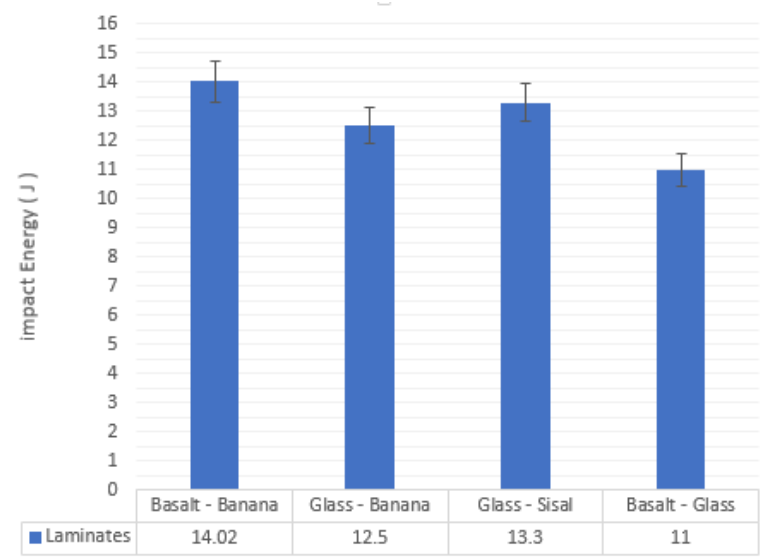

Figure 7: Comparison of Impact Energy absorbed by different Laminates [10] [4]

The impact energy of the sample was found to be $14.02 \mathrm{~J}$ by observing the reading from the dial on the pendulum. The impact resistance was calculated as $4673.33 \mathrm{~J} / \mathrm{m}$ using the following formula

\section{Impact Resistance=Impact Energy/ Width}

The bar graph in figure 7 compares the energy absorbed by different types of laminates on impact. It can be seen that the impact energy of basalt-banana laminates is $12.16 \%$ more than that of glass-banana laminates. We can also observe that sisal fiber with glass fiber has better energy absorbing capacity compared to banana fiber with sisal fiber as banana fiber has less cellulose content compared to sisal fiber[11]. There is an increase in Impact energy by $27.45 \%$ on addition of banana fiber to basalt fiber instead of glass fiber due to good impact absorption capabilities of natural fibers banana fiber has less cellulose content compared to sisal fiber.

\section{Hardness Properties}

The measured hardness values of all the three laminates are presented in figure 8 . From the test it is found the hardness increases with the addition of basalt fabric layers in substitution to glass fiber. The hardness value of the referred banana GFRP laminate is 17.56 whereas the hardness value of banana BFRP is 19.5.



Figure 8: Hardness test Result of Laminates 


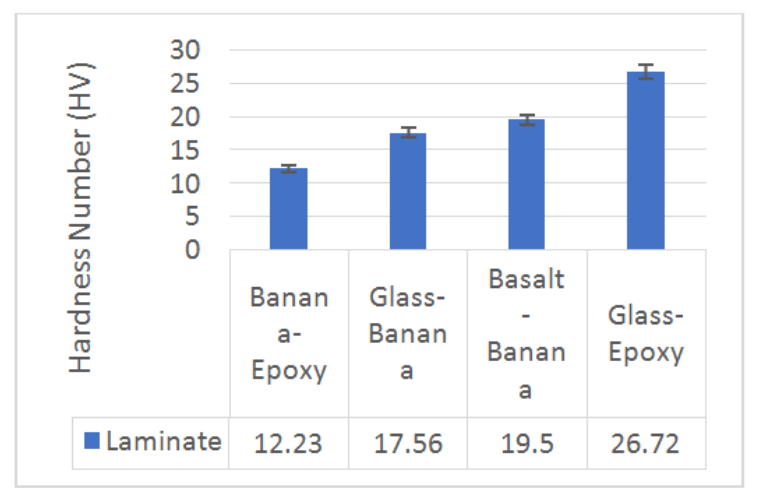

Figure 9: Vickers Hardness value for Various Laminates [9]

Figure 9compares the hardness number in Vickers scale of various epoxy laminates. It is evident that the basaltbanana epoxy laminates are $60 \%$ harder than the banana-epoxy laminates, i.e. additional surface hardness provided by basalt fabric layer increases the hardness of the laminate. Usage of glass fiber sheets with the banana fiber gives better surface hardness of 17.56 to the composite, but substituting glass with basalt fiber layers makes the composite $11 \%$ much harder.

\section{Water Absorption Properties}

The water absorption behavior, specimens were immersed in water at $23^{\circ} \mathrm{C}$ as per ASTM D 570

\section{Water Absorption \%=((wet weight-dry weight $) /($ dry weight $)) * 100$}

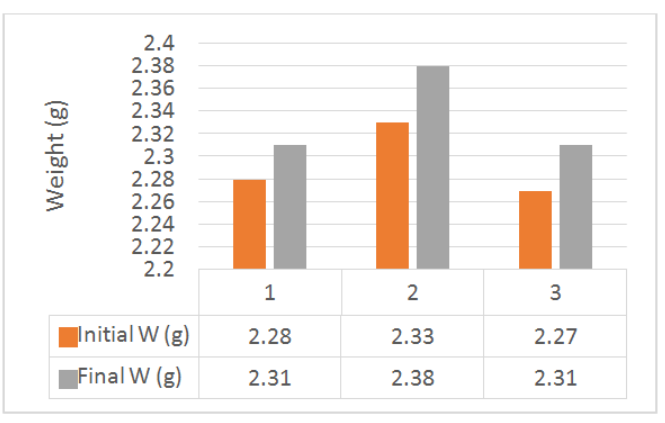

Figure 10: Weight Change of Samples

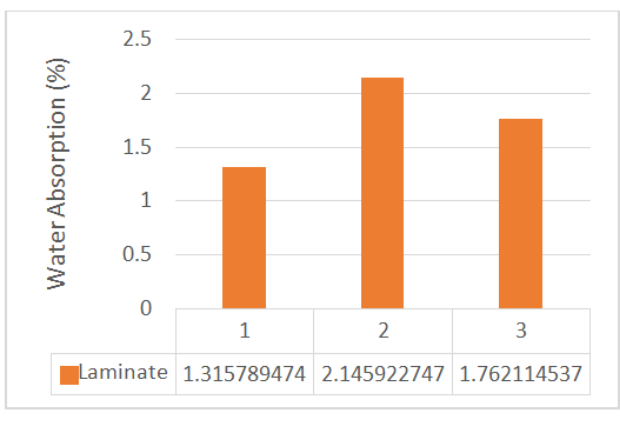

Figure 11: Water Absorption Percentage

From figure 10 it can be found that maximum water absorption is observed in sample 2 and overall percentage change in weight due to water absorption is $1.744 \%$.

\section{SEM Analysis}

In Impact test, maximum fiber breakage was observed and the impact surface under observation was much smooth compared to other samples the crack on the surface due to the poor bonding between the fibers and matrix.

In three point bending test, the crack propagated from the outermost layer to the inner layer of the laminate which implies that delamination tends to occur at the interface of two different layers. Basalt fiber has an important role in defining flexural properties for hybrid laminates. Most of the load was absorbed by basalt fibers and the remaining part of the load was transmitted to the banana fibers. 
The failure of the specimen in a tensile test occurred when the banana fiber failed and started propagating to the adjacent layers of composite. Due to intercalated stacking of basalt and banana the ultimate tensile strength was more due to the added basalt layer in between.

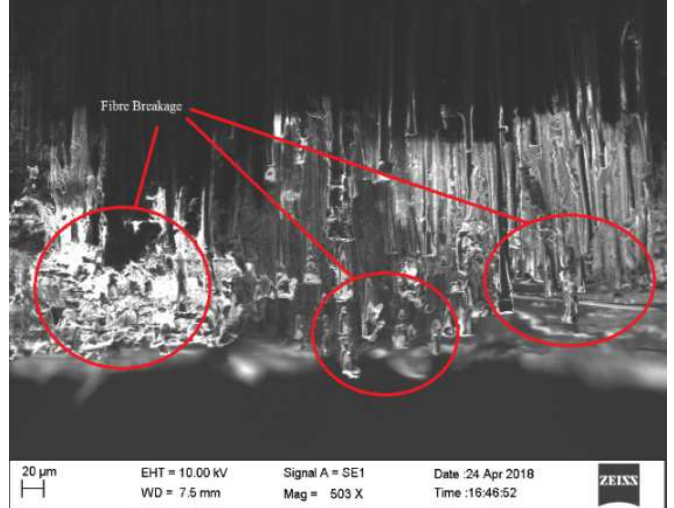

Figure 12: Fiber Breakage in Impact Test Specimen

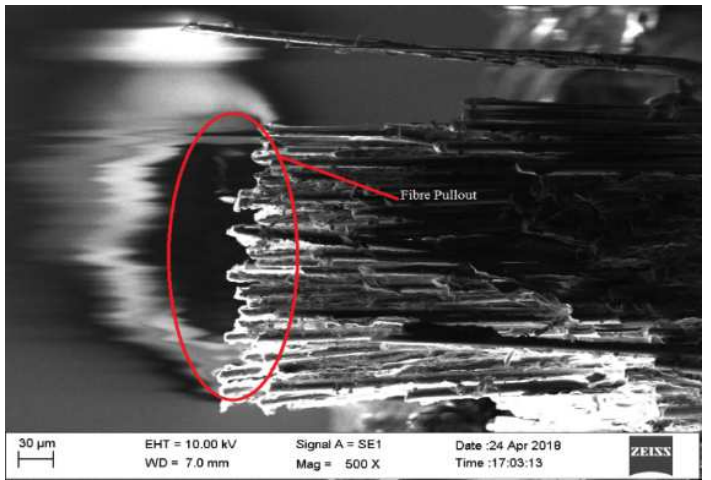

Figure 14: Fiber Pull-out in Flexural Test Specimen

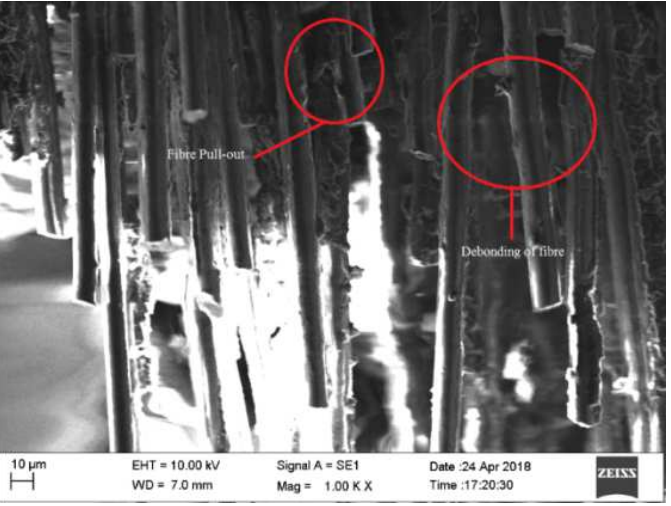

Figure 13: De-Bonding and Fiber Pull-out in Tensile Test Specimen

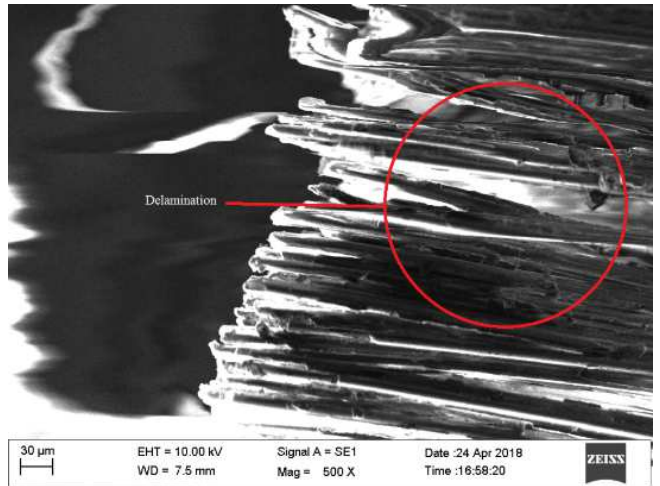

Figure 15: Delamination of Basalt Layer in Flexural Test Specimen

\section{CONCLUSIONS}

The ultimate tensile strength observed was $88.73 \mathrm{MPa}$ for the three layers of basalt fiber laminate. The performance of the laminates was better for flexural strength and maximum flexural strength of $354.3 \mathrm{MPa}$ was observed during the test. The banana-basalt laminates showed improvement in impact energy of $14.02 \mathrm{~J}$ during the test. From the Hardness test it is found that the Vicker's hardness number of the laminate is 19.02. The maximum increase in weight percentage was found to be $2.14 \%$. Thus the basalt hybrid composites can be used as an alternative for glass hybrid composites for various applications.

\section{REFERENCES}

1. M.R. Sanjay, P. Madhu, Mohammad Jawaid, P. Senthamaraikannan, S. Senthil, S. Pradeep, Characterization and properties of natural fiber polymer composites: A comprehensive review, Journal of Cleaner Production, Volume 172, 2018, Pages 566581, ISSN 0959-6526.

2. W. Paul, I. Jan, V. Ignaas, Natural fibres: can they rep lace glass in fiber reinforced plastics? Comp. Sci. and Tech. 63 (2003) 1259-1264. 
3. N. Venkateshwaran, A. Elaya Perumal, D. Arunsundaranayagam, Fiber surface treatment and its effect on mechanical and visco-elastic behavior of banana/epoxy composite, Materials and Design 47 (2013) 151-159.

4. V.P. Arthanarieswaran, A. Kumaravel, M. Kathirselvam, Evaluation of mechanical properties of banana and sisal fiber reinforced epoxy composites: Influence of glass fiber hybridization, Materials \& Design, Volume 64, 2014, Pages 194-202, ISSN 0261-3069.

5. KM, A. F., \& Varghese, S. (2014). Behavioural Study of Steel Fiber And Polypropylene Fiber Reinforced Concrete.

6. Amuthakkannan, P., Manikandan, V., Jappes, J. T. W., \& Uthayakumar, M. (2012). Influence of stacking sequence on mechanical properties of basalt-jute fiber-reinforced polymer hybrid composites.

7. Bhoopathi, R., Ramesh, M., \& Deepa, C. (2014). Fabrication and property evaluation of banana-hemp-glass fiber reinforced composites. procedia engineering, 97, 2032-2041.

8. M. Boopalan, M. Niranjanaa, M.J. Umapathy, Study on the mechanical properties and thermal properties of jute and banana fiber reinforced epoxy hybrid composites, Composites Part B: Engineering, Volume 51, 2013, Pages 54-57, ISSN 1359-8368.

9. Cristiano Fragassa, Ana Pavlovic, Carlo Santulli, Mechanical and impact characterisation of flax and basalt fiber vinylester composites and their hybrids, Composites Part B: Engineering, Volume 137, 2018, Pages 247-259, ISSN 1359-8368,

10. Doshi, A., \& Karolia, A. (2016). Optimization of Enzyme Treatment for Banana Fiber.

11. Muhamad Shahirul Mat Jusoh, Carlo Santulli, Mohd Yazid Mohd Yahya, NurIzan Syahriah Hussein and Hariz Ahmad IsrarAhmad (2016) Effect of Stacking Sequence on the Tensile and Flexural Properties of Glass Fiber Epoxy Composites Hybridized with Basalt, Flax or Jute Fibers. Mater. Sci. Eng. Adv. Res 1(4): 19-25.

12. V.S. Srinivasan, S. R. Boopathy, D. Sangeetha, B. V. Ramnath, Evaluation of mechanical and thermal properties of bananaflax based natural fiber composite, Materials and Design;2014;60: 620-627.

13. M. Rajesh, Jeyaraj Pitchaimani, N. Rajini, Free Vibration Characteristics of Banana/Sisal Natural Fibers Reinforced Hybrid Polymer Composite Beam, Procedia Engineering, Volume 144, 2016, Pages 1055-1059, ISSN 1877-7058. 